\title{
Analysis on the Historical Evolution Characteristics of China's Industrialization Based on Open Conditions
}

\author{
Xin $\operatorname{Jin}^{1,2}$ \\ ${ }^{1}$ School of History and Archives, Yunnan University, Kunming, Yunnan, 650091 \\ ${ }^{2}$ School of Marxism, Kunming University, Kunming, Yunnan, 650214
}

Keywords: Open Condition; Industrialization; Evolutionary Characteristics

\begin{abstract}
The first stage of the historical evolution of China's industrialization under open conditions is the transition from heavy industry to light industry during the period from the Sixth Five-Year Plan to the Eighth Five-Year Plan. Under this political and economic reform, the need to adjust the industrial structure of the national economy requires industrialization. The distribution and market advancement are targeted. The development trend of the national economy is inevitably adjusted in terms of industrial output value under the premise of actively utilizing foreign capital and market demand. The adjustment of industrial output value at this stage is reflected in the principle that the ratio of agricultural output value, light industrial output value and heavy industry output value tends to be balanced in the process of lowering the traditional heavy industry output value index. The balance between agricultural output value, light industrial output value and heavy industry output value is intrinsically linked with the promotion of market demand. Therefore, the industrialization transformation adjustment at this stage still has the characteristics of pursuing the development path of high-input and high-output industrialization. The background of industrialization adjustment in the second phase is based on the growth of domestic market demand and the impact of the global economy. On the basis of the fact that the reserves of domestic industrial resources have not met the demand for industrial output growth, the development path of industrialization is in line with the requirements of social and economic transformation and reform. The characteristics of the second phase of industrialization evolution are mainly characterized by the transformation characteristics of economic benefits, competitiveness and sustainable development compared with the first stage of epitaxial industrialization.
\end{abstract}

\section{Introduction}

The process of China's industrialization under open conditions shows two distinct stages of industrialization from light to light and from first to highest. The historical evolution of China's industrialization under these two stages has a phased feature. The extension of industrialization, as an important foundation of global economic development, has a high degree of stage in the development of China's industrialization. The staged industrialization development has played a sufficient role in promoting the characteristics of the times and the evolution of history on the basis of open conditions. This paper comprehensively analyzes and summarizes the characteristics of China's industrialization evolution based on open conditions. This process analyzes the data of China's industrial output since the sixth five-year plan, and thus shifts from heavy industry to light industry to light industry to high-end. The two stages of manufacturing development explore the historical evolution of China's industrialization. At the present stage, the level of industrialization and the value of China's industrialization are increasing at the same time, including the transformation from primaryization to advancedization of light industry, the transformation of industrial products from low growth to high value-added, and the adjustment of light industrial structure at various stages. 


\section{The Heavy Industry Transition Light Industry Stage}

The industrial plan in the Sixth Five-Year Plan formulated in 1980 shows that the road to industrialization in China has shifted from heavy industry to light industry. The general outline proposed in the Sixth Five-Year Plan requires that the total output value of China's industry and agriculture should reach an average annual growth rate of four percentage points to five percentage points within the sixth five-year plan from 1981 to 1985. The average annual growth rate of the planned indicators by four percentage points to five percentage points has a significant increase compared with the growth rate of the previous five five-year plans [1]. The indicators for the secondary industry's planned indicators to grow by an average of four percentage points to five percentage points have shown a significant downward trend since the first five-year plan. The introduction of the industrial indicators of the sixth five-year plan has a direct relationship with the political policies under the reform and opening up. The reform of economic policy has made the economic model begin to get rid of the fixed output value of industrialization under the planned economy. The output of industrial products directly depends on the demand of the market. Therefore, the adjustment and change of industrial output value at this stage is mainly determined by policies. Its specific performance is that the direct adjustment of industrial and agricultural output value is to improve the gross national product and industrial economic benefits by reforming the economic structure. The change in the distribution ratio of the total capital investment of the sixth five-year plan and the total investment of the fifth five-year plan is an important manifestation of the heavy industry transition to the light industry stage. During the Sixth Five-Year Plan period, the proportion of investment in industrial technological transformation from 1981 to 1985 reached $40 \%$ of the total investment in infrastructure, which is more than the average annual growth rate of the previous five five-year plan [2]. The total investment in culture, education, science and health accounted for $16 \%$ of the country's total fiscal expenditure, and increased by 5 percentage points over the fifth five-year plan. From the data of total infrastructure investment and national fiscal expenditure, it can be concluded that the adjustment of China's industrialization from 1981 to 1985 during the sixth five-year plan period showed the stage of heavy industry transition to light industry. From the perspective of industrial value-added analysis, the comparison of the data during the sixth five-year plan can be concluded that the total value added of China's light industry output increased by seven from 1981 to 1985 during the sixth five-year plan period. Ten percentage points, the annual growth rate of light industry has maintained a high growth rate of $17 \%$ per annum. However, during the sixth five-year period from 1981 to 1985, the proportion of China's light industry's value-added in the gross national product showed a downward trend year by year.

The changes in industrial output during the seven-year plan period from 1986 to 1990 were mainly divided into two aspects of various aspects arising from sustained economic development and various aspects arising from the sustainable development of the economy. The main problems caused by the sustained economic development are mainly the increase of factors that are not conducive to the structural adjustment of the national economy caused by overheating of the economy. The various problems caused by the sustainable development of the governance economy are mainly based on the sustainable development of the economy as the main task of the rectification period. In the seventh five-year plan, the output value of China's light industry between 1986 and 1990 increased by 70\%. In the period of economic overheating, the growth rate of young industrial output reached 8.7-15.5 percentage points per annum from 1986 to 1988. In the period from 1988 to 1990, the growth rate of the rectification stage showed a sharp decline. The gross national product during the seventh five-year plan period remained in an overall stable state. The historical evolution of industrialization under the reform of China's socialist market economic system after the 14th National Congress of the Communist Party of China developed to a new stage. First, the political report of the 14th National Congress established the non-public economy as the main component of the socialist market economy. The gradual opening up of the private economy in the report of the big economic policy is the main reason for the adjustment of industrial output value. Under the concept of common development of multiple economies with public ownership as 
the mainstay, China's industrialization has entered a period of growth in light industrial exports. The rapid development of China's industrialization directly promoted the reform of the economic system. The market enterprise has developed and improved its management system in the process of transforming its management functions. Under the concept of agricultural industrialization, the national economic expenditure structure and the continuous adjustment and improvement of the industrial structure show the acceleration of the tertiary industry. The economic reform in this stage is mainly based on the fundamental reform of the distribution system as an important feature of the historical evolution of industrialization [3]. The reform of the distribution system based on the distribution of labor and multiple distributions highlights the efficiency and innovation of the market economy. The historical evolution of China's industrialization under open conditions emphasizes the efficient application of foreign capital, technology and management operations under the economic structure at this stage.

In March 1993, the Central Economic Conference improved the growth rate of 6 percent of the original plan to a growth rate of 8 percent to $9 \%$ after scientifically demonstrating the revision of the eighth five-year plan industrial output value. . The practical approach adopted in policy to achieve the economic goals set by the 14th National Congress fully applies the dialectical relationship between generality and particularity in economic relations. From 1991 to 1995, the eight regions of the country were based on the economy. The difference in volume has liberalized the overall indicators. Therefore, the indicators of industrial output value in the regions with large economic volume and obvious regional advantages have completed the indicators earlier. The industrial output value specified in the eighth five-year plan in this context was fully completed by the end of 1995. The average annual growth rate of China's gross national product during the entire eighth five-year plan reached 12 percent. During the Eighth Five-Year Plan period, China's gross national product reached more than 580 billion U.S. dollars from 1991 to 1995. With the full completion of economic indicators, the economic goals proposed by the 14th National Congress have been completed five years ahead of schedule. During the Eighth Five-Year Plan period, China's agricultural output value reached an average annual increase of $4 \%$. The industrial output value reached an average annual growth rate of 18\%. From 1991 to 1995, the average annual growth rate of urban per capita income and rural per capita income in China reached 8\% and 5\% respectively. On the basis of the sharp increase in industrial output, the overall poverty population in the country has dropped by 45 million, while the natural growth rate of the population has dropped by five percentage points. The period from 1991 to 1995 of the Eighth Five-Year Plan as the fastest and most stable period of China's economic development directly determines the future direction of China's industrialization [4]. The one-five-day work realized by the employees during the Eighth Five-Year Plan period is a direct reflection of the economic development during the Eighth Five-Year Plan period. Although China's industrialization development has maintained the characteristics of extensional development during this period, the active capital market and the shortage of labor during the Eighth Five-Year Plan period have made the light industrial-oriented industrial structure actively adopt value-added and transformation as its development direction. The value added of the light industry at this stage also presents a two-stage change. The annual growth rate between 1991 and 1993 was always higher than 12 percent, and from 1993 to 1995 it fell to 12 points. During the Eighth Five-Year Plan period, the overall output value of light industry remained above $30 \%$. This is directly related to the market-oriented reform of China's economic system during the Eighth Five-Year Plan. The increase in economic marketization and social economic activity is reflected in the rapid transformation of industrialization history.

\section{The Regional Distribution Characteristics of China's Industrialization}

After the Eighth Five-Year Plan, China's industrial transformation basically completed the framework reform of the social market economic system. Throughout the 1990s, the regional layout of light industry under the open conditions moved from point to point to the southeastern coast of China [5]. The regional layout of heavy industry is concentrated in China's central and western industrial cities. The difference in the layout of light and heavy industries is the main feature of the 
second phase of China's industrialization history. The light industry's active capital under the economic system reform has completed its overall regional layout through the accumulation of private capital and the transfer of foreign capital. On the one hand, this regional layout has a major relationship with the completion of the accumulation of the original capital of private enterprises, the transfer of foreign-invested industries, and the large investment in state-owned capital. On the other hand, the advantages of a large number of high-quality surplus labor in the coastal areas and the advantages of regional concentrated light industrial resources and The developed logistics system is also the basis and premise for constructing the layout characteristics of light industry. The Pearl River Delta Industrial Center, the Changsan Delta Industrial Center and the Bohai Sea Industrial Center formed by the second phase of China's industrialization history are the obvious responses to the concentrated distribution of China's industrialized areas. The type and quality of light industry in the second phase of China's industrialization history under open conditions have been fully developed. Among them, light industry, such as textile, clothing, medicine, food, electronic information, automobile manufacturing and aerospace manufacturing, has achieved dual development of quality and quantity under the joint promotion of private capital and foreign capital. In the framework of policy, China's industrialization has completed the transformation from a planned economy to a multi-component of the ownership economy. The role of the market and the coexistence and improvement of macroeconomic regulation have led to the transformation of the socialist market economy. The most obvious feature in the evolution of the second stage is the blind pursuit of high efficiency, high index and high speed in the first stage of industrialization. The second stage of industrialization is based on the adjustment of market needs and the regulation of macro policies. From the first stage of the industrialization of the index of industrialization, the ratio of heavy industry output, light industrial output value and agricultural output value to the second stage of light industrial export output value-oriented strategic transformation, the second stage of light industrial export output value based on the concentration of China's light industry regional layout Under the circumstance, the light industry export strategy actively utilizes the two characteristics of the circulation of international capital and the development of foreign markets. Therefore, in the evolution of industrialization history, the development of regional productivity of light industry has been fundamentally changed based on the gradient of the balanced development of China's industrialized regions.

The main reasons for the regionalization of China's industrialization after the Eighth Five-Year Plan include three aspects. First, the Chinese industrial market has been suppressed for a long time under the planned economic system. The in-depth reform of the economic system has led to the planned economic system. The suppressed industrial market has been released, and private capital has completed the process of accumulating the original capital rapidly in this release. The demand for the industrial market under the planned economic system has been fundamentally transformed after the completion of capital accumulation. In turn, the industrial production value has increased substantially from the production, capital and consumption sectors of the market. Secondly, the most important reason for China's industrialization layout to complete the regionalization is the reform of the economic system. Under the reform of the economic system, the promotion of light industry development includes the relaxation of credit system and taxation system, which enables private capital, state-owned enterprises and foreign-funded enterprises to obtain considerable profits. On this basis, the coastal region can quickly complete the industrialized regional layout after relying on its own location advantages. The high-quality labor force that has been cultivated for a long time under the planned economic system has been released to a considerable extent in the industrialization reform. China's continued investment in education has made the labor force generally have a systematic basic education level. The growth of per capita income in the coastal areas while the economic profits are growing also makes the regional labor force turn to the coastal areas. The labor force with a generally high overall quality has greatly improved the competitiveness of light industrial enterprises' products and management levels [6]. Under this background, the light industry enterprises have been significantly concentrated under the premise of fully absorbing high-quality labor, which further promotes the transformation of the class and the 
expansion of domestic market demand. In addition, the continuous opening of economic policies has also brought about the essential improvement of technical means and management means of foreign capital in the process of capital inflow to the regional center.

\section{Conclusion}

The historical evolution of China's industrialization has undergone significant phase changes with the reform of the social and economic system. Under this change, the overall level of China's industrialization has adapted from the extension of the first stage to the regionalization of the second stage. The scale and layout of light industry and heavy industry in the historical evolution of China's industrialization have been developed in a regionally centralized manner. The irrational factors in the industrialization structure of the current reforms require the government to actively promote the evolution of industrialization history from the global economic trends and China's role in the market economy.

\section{References}

[1] Zheng Yougui. The Historical Position of the National Agricultural Development Program from 1956 to 1967_ An Analysis of the Realization Path of Agricultural Productivity in the Process of National Industrialization [J]. Modern philosophy, 2017(1): 43-50.

[2] Zhang Haojun. Social Security and Economic Development from the Perspective of Historical Comparison—_Based on the Analysis of Industrialization Process in Some Countries in Europe and America[J].Lanzhou Academic Journal,2017(9):176-185.

[3] Liu Jiajia, Ding Junjie. The Construction and Reflection of the Concept of Chinese Elements in Advertising Discourse: A Perspective of Historical Evolution [J]. Journal of Zhejiang Communication University, 2017(6): 23-28.

[4] Xie Lujiang. On the Historical Logic of the Development of China's Socialist Public Ownership Economy [J]. People's Forum • Academic Frontiers, 2017 (9): 90-95.

[5] Wang Wei, Hu Huilin. Several Basic Characteristics of China's Cultural Conditions__based on the Evaluation and Analysis of Chinese Cultural Development Index System (CCDIS) [J].Journal of Central China Normal University (Humanities and Social Sciences), 2017, 56(2)): 74-82.

[6] Yazny Apro, Li Xuedong. The Enlightenment of China's Reform and Opening Experience on South Africa's Industrialization [J]. West Asia Africa, 2017(1): 63-86. 